\title{
O papel do consumidor na política nacional de resíduos sólidos: uma perspectiva ética
}

The role of consumers in National Policy for Solid Waste: an ethical perspective

Renata Cristine Ogassavara ${ }^{1}$

\begin{abstract}
Resumo
A lei 12.305 , de 2.8.2010, instituidora da Política Nacional de Resíduos Sólidos, sinaliza a imperiosidade por mudanças coletivas nos atuais padrões de consumo. Ao ser analisada sob o ponto de vista ético do princípio responsabilidade de Hans Jonas, a responsabilidade compartilhada pelo ciclo do produto criada pela norma indica que a lógica tradicional de reciprocidade entre direitos e deveres não tem mais suporte no cenário da nova modernidade.
\end{abstract}

Palavras Chave: Direito; Consumidor; Ética; Políticas Públicas; Pós-modernidade.

\section{Abstract}

Federal Law 12.305, 8.2.2010 - National Policy for Solid Waste - represents the urge of a transformation in current patterns of consumption. The figure of shared responsibility for the product cycle created by it indicates that the traditional idea of reciprocity between rights and duties is no longer supported by the scenario of new modernity, when it is analyzed from the viewpoint of Hans Jonas' ethical imperative of responsibility.

Keywords: Law; Consumption; Ethics; Policies; Post modernity.

\section{Introdução}

Sem contabilizar o descarte clandestino, os brasileiros produziram 195.000 toneladas de lixo em $2010^{2}$; número esse que representa um acréscimo de $6 \%$ em relação ao

\footnotetext{
${ }^{1}$ M estranda em Direito da Pontifícia Universidade Católica de São Paulo - PUC/SP. Analista do Banco Central do Brasil.

${ }^{2}$ Estatística da Associação Brasileira de Limpeza Pública e Resíduos Especiais - Abrelpe.
} 
ano anterior ${ }^{3}$ e também um descompasso com a capacidade de absorção pelos atuais sistemas de destinação dos resíduos (VIALLI, 2011).

No que tange à produção nacional de resíduos sólidos e sua relação com o direito constitucional ao meio ambiente ecologicamente equilibrado, 0 ano de 2010 foi emblemático, pois durante o seu curso foi instituída a Política Nacional de Resíduos Sólidos (PNRS) por meio da Lei 12.305, a qual criou expectativa por um programa de ação em harmonia com as demais políticas públicas, em especial, com a Política Nacional do Meio Ambiente (Lei 6.938, de 31.8.1981), com a Política Nacional das Relações de Consumo (parte da Lei 8.078, de 11.9.1990) e com a Política Nacional da Educação Ambiental (Lei 9.795, de 27.4.1999).

Afinal, como leciona a professora Maria Paula Dallari Bucci (2006, p.39):

Política pública é o programa de ação governamental que resulta de um processo ou conjunto de processos juridicamente regulados - processo eleitoral, processo de planejamento, processo de governo, processo orçamentário, processo legislativo, processo administrativo, processo judicial - visando coordenar os meios à disposição do Estado e as atividades privadas, para a realização de objetivos socialmente relevantes e politicamente determinados. (BUCCl, 2006, p.39).

Com relação às relações de consumo, a lei da PNRS é expressa ao assumir a ecoeficiência como princípio, o qual compreende a árdua tarefa de compatibilizar a produção de bens e serviços assecuratórios das necessidades da sobrevivência e da qualidade de vida humanas com o mínimo impacto ambiental possível, bem como com a promoção da redução do consumo de recursos naturais até - pelo menos - a capacidade de sustentação do planeta (art.6ํ, V).

Reforçando a imperiosidade coletiva de modificação de padrões de consumo, a lei estabeleceu o consumo sustentável dentre seus objetivos (art. 70, XV) e criou a responsabilidade compartilhada pelo ciclo de vida dos produtos destinada aos fabricantes, importadores, distribuidores e comerciantes, aos consumidores e aos titulares dos serviços públicos de limpeza urbana e de manejo de resíduos sólidos (art.3ํ, XVII).

\footnotetext{
${ }^{3}$ No Estado de São Paulo, o aumento foi de $9 \%$ por habitante que corresponde à média individual diária de $1,382 \mathrm{~kg}$ de lixo (GERAQUE, 2011).
} 
Além disso, criminalizou inclusive a destinação doméstica inadequada, impondo pena de reclusão e multa à conduta de descarte em desacordo com a lei ou com seus regulamentos - alteração do art. 56 da Lei 9.605, de 12.2.1998, da "Seção III - Da Poluição e outros crimes ambientais".

A partir deste breve cenário, já se delineiam várias questões sobre a lei da PNRS, em especial, sobre o conteúdo e consequências jurídicas da responsabilidade compartilhada sobre o ciclo do produto - tema sobre o qual debruça-se intensamente a doutrina - uma vez que a definição trazida pela lei afasta-se dos modelos clássicos consagrados pelo Direito. Seria uma espécie de solidariedade? Subsidiariedade? É válido o pressuposto da vulnerabilidade?

Isto posto e tendo em conta tais dificuldades, o objetivo deste estudo volta-se também à compreensão da responsabilidade do consumidor na PNRS, porém sob a ótica da ética ambiental, particularmente, sob a perspectiva do princípio responsabilidade de Hans Jonas (1903 -1993), pois como afirma a professora Cristiane Derani, a imposição de novas políticas públicas apenas ocorre porque há necessidade de substituição de uma ética por outra orientada por novos valores (2006, p.134).

Assim, o trabalho dedica-se em primeiro lugar a analisar as prováveis causas da produção de externalidade negativas pela sociedade atual - como a excessiva quantidade de resíduos sólidos - e em seguida, procura demonstrar a incapacidade da ética tradicional em lidar com os problemas surgidos a partir desta nova modernidade. Em segundo lugar, apresenta a solução ética do filósofo alemão Hans Jonas, estabelece a relação desta com a PNRS.

\section{Os novos problemas da nova modernidade}

Por que razão foi preciso criar uma PNRS se desde sempre a população humana produziu resíduos e a natureza sempre foi capaz de absorvê-los, deve ser o primeiro ponto a ser esclarecido. A questão é complexa.

Ora, pode-se pensar por um lado que o lixo passou a ser um problema porque a população humana cresceu vertiginosamente e com ela, a produção de resíduos, de sorte que o limite natural de ciclagem foi ultrapassado. A título de ilustração, segundo os dados históricos do Instituto Brasileiro de Geografia e Pesquisa (IBGE), a população brasileira que 
era de 9.930.478 indivíduos em 1872, passou a 190.755.799 habitantes em 2010, isto é, houve um aumento de 180.825.321 de seres humanos aproximadamente nos mesmos limites espaciais em um período de tempo relativamente curto.

Por outro lado, é possível crer também que o lixo passou a ser um problema, pois a economia de recursos naturais ainda não é um valor incorporado pela cultura nacional. A abundância quali e quantitativa de recursos naturais no território e a ausência catástrofes naturais ou provocadas pelo homem capazes de causar escassez generalizada no decurso da breve história do país podem ser explicações para o descaso generalizado com a contenção da utilização, com o reaproveitamento e com a reciclagem.

Além dos fatores apresentados - crescimento populacional, riqueza de recursos naturais e ausência de cultura da economia - houve ainda a elevação do consumo individual após a 2 ${ }^{\underline{a}}$ Guerra M undial com a consolidação da sociedade de consumo nacional.

É necessário pontuar que o consumo como produto histórico de um processo de profundas mudanças sociais, econômicas e culturais ocorridas ao longo de séculos, já havia se firmado na Europa durante o século XIX, todavia no Brasil as características da sociedade de consumo, quais sejam, produção em série, distribuição em massa de produtos e serviços, publicidade em larga escala, contratação por meio de contrato de adesão e generalização do crédito do consumidor (SODRÉ, 2007), somente se firmaram na segunda metade do século $X X$.

A Revolução Industrial sempre foi apontada como o marco histórico fundamental destas transformações, todavia constitui apenas uma face do fenômeno: a da oferta. 0 outro lado da moeda - a Revolução do Consumo - corresponde às modificações sofridas pela demanda em função das alterações do modo de produção (M CCRACKEN, 2003). Em outras palavras, em contrapartida às tecnologias de produção em série tomaram corpo a distribuição e o consumo em massa e a expansão do crédito.

Essa modificação abrupta do consumo deu-se em função da adoção de novos estilos de vida impulsionada pelas emergentes técnicas de "marketing" e de publicidade de massas, as quais objetivaram modificar o significado social de bens e serviços, agregando-Ihes valor e criando uma dependência social aos novos bens, às práticas de consumo e por fim, às marcas em si (KLEIN, 2004). 
O filósofo francês Gilles Lipovetsky (2007) acresce que a fase de sociedade do consumo ou sociedade do desejo - caracterizada pelas grandes cadeias de lojas e de redes de distribuição - já foi transposta em meados da década de 70 do século XX. Atualmente, segundo o autor, vive-se na sociedade do hiperconsumo - ou sociedade do consumo emocional - formada por turboconsumidores bem informados e guiados pelo hedonismo - e pelo consumo como finalidade em si - em um mundo de produção em massa especializada e segmentada.

Em resumo, o desenvolvimento tecnológico aliado à consolidação da sociedade do consumo - com seus consectários tais como desperdício e individualismo - bem como a falta de visão de futuro e planejamento no que tange aos produtos sintéticos por exemplo foram responsáveis pela produção de efeitos colaterais indesejados que se voltaram contra a existência dos seres humanos. Neste contexto, a PNRS visa estabelecer processos coordenados de um programa governamental para gerenciar, reduzir, reutilizar e reciclar uma parcela destes subprodutos da nova modernidade.

\section{0 vazio ético}

Compatriota e contemporâneo de Hans Jonas, o sociólogo Ulrich Beck (1944) constatou - às vésperas do acidente na usina nuclear de Chernobyl (1986) no norte da Ucrânia - que o conhecimento tecnológico, outrora libertador do homem, passara à condição de produtor de ameaças. Percebeu ele que os riscos da nova modernidade são supranacionais, sistemáticos, irreversíveis e imperceptíveis de modo imediato.

No caso específico do mau gerenciamento dos resíduos sólidos, tais características podem ser facilmente identificadas ao se pensar na possibilidade de contaminação lenta e gradativa do solo e de lençóis freáticos atingindo a saúde de indivíduos de várias sociedades concomitantemente, bem como violando a qualidade de vida daqueles que ainda nem nasceram.

Ressalta-se que o termo sociedade é aqui utilizado de modo amplíssimo, sem distinções entre sociedades de Primeiro e de Terceiro Mundo, ou entre classes, uma vez que os riscos da nova modernidade democraticamente atingem a todos sem distinção, sem limitação por fronteiras. Certamente que, apesar deste caráter universal, os que carecem de recursos financeiros são os que mais sofrem e mais sofrerão com eles, porém a situação dos 
ricos não é confortável e nem segura, pois a chegada dos perigos modernos à suas vidas parece ser uma certeza condicionada apenas pelo tempo.

Contemplando este cenário, Hans Jonas contrapôs as lições de Kant (1724-1804) aos problemas da nova modernidade, desvelando primeiramente as características da ética tradicional, a saber, neutralidade, antropocentrismo, constância, ação de curto prazo e contemporaneidade (JONAS, 2006, p.35-37), as quais, a jurista portuguesa Maria da Glória F.P.D. Garcia (2007, p.82-89) sintetizou em proximidade, acessibilidade e não cumulatividade.

Em termos gerais, isto vale dizer que para a ética tradicional somente há espaço para a relação direta de seres humanos com seres humanos e deles consigo próprios (antropocentrismo), de sorte que o trato sobre objetos não humanos não compreende 0 mundo eticamente significativo (neutralidade).

Além disso, a ética tradicional encontra-se circunscrita no espaço e tempo de vida previsível de um ser humano, de sorte que os destinatários das ações são os indivíduos contemporâneos (contemporaneidade) e pertencentes aos círculos próximos do agente, como as pessoas de sua família, seus amigos ou colegas de trabalho (proximidade), ou seja, sua perspectiva é de curto prazo.

A ação ética tradicional também caracteriza-se por não demandar o domínio de conhecimentos específicos para a sua realização, pois basta o bom senso para que a honestidade, a bondade e as demais virtudes possam se manifestar (acessibilidade) e por fim, toda a conduta ética tradicional implica em partir da escolha inicial, ainda que se trate de uma ação repetitiva (não cumulatividade).

Entretanto, a sociedade da nova modernidade - sociedade pós-moderna, sociedade do risco, sociedade do consumo, sociedade do hiperconsumo, sociedade da informação, dentre tantas denominações possíveis - lida com problemas transindividuais e transgeracionais incompatíveis com a lógica da reciprocidade de imperativos categóricos ${ }^{4}$

\footnotetext{
${ }^{4}$ O Dicionário de Filosofia de Niccola Abbagnano (2007, p.628) registra que imperativo é um "termo criado por Kant, talvez por analogia com o termo bíblico "mandamento", para indicar a fórmula que expressa uma norma da razão (...). Para o homem, norma da razão é uma ordem, pois a vontade humana não é a faculdade de escolher apenas o que a razão reconhece como praticamente necessário, ou seja, como bom. Se assim fosse a norma da razão não teria caráter coativo e não seria uma ordem. Isso acontece com os seres dotados de uma vontade santa, de uma vontade que está necessariamente de acordo com as razão e que só pode escolher também segundo a inclinação sensível, a lei da razão assume para ele a forma de ordem e por isso sua expressão é um I. (imperativo) (Crít. R. Prática, I, cap. III). Portanto, a palavra I. Não passa de outro nome para a
} 
kantianos, uma vez que a dimensão de futuro não se apresentava dentre as aflições do filósofo.

\section{A ética do futuro}

Ao contrário das situações resolvidas pela ética tradicional, as relacionadas aos problemas da nova modernidade caracterizam-se pela necessidade de conhecimento técnico altamente especializado, bem como de planejamento de ações de longo prazo, ambos sob o fio da irreversibilidade do dano produzido e da ameaça às gerações futuras de seres viventes (humanos e não humanos).

Assim, tanto a produção científica deve passar pelo crivo do juízo ético - "Tenho permissão para apostar a totalidade dos interesses dos outros?" (JONAS, 2006, p.85) - como a aplicação da ética passa pela avaliação de risco da ciência - "Há de se formar uma ciência da previsão hipotética, uma futurologia comparativa" (JONAS, 2006, p.70). Neste sentido, 0 pensamento de Hans Jonas encerra a "heurística do medo" (JONAS, 2006, p.70), porém 0 autor esclarece que "o medo que faz parte da responsabilidade não é aquele que nos aconselha a não agir, mas aquele que nos convida a agir" (JONAS, 2006, p.351).

Da obra principal do autor alemão, depreende-se não se trata de mera faculdade de agir, mas sim de "freios voluntários" - quase que imperativos - fundados na responsabilidade para com a Humanidade e decorrentes do poder excessivo atingido pelos seres humanos. Todavia, a Humanidade é por ele conceituada como o legado de cultura e conhecimento acumulados até os dias de hoje provenientes da genialidade, do esforço e do talento de muitos ao longo dos séculos e não entendida como o compromisso com o homem ou mulher concretos.

Para Jonas, a Humanidade não tem direito ao suicídio - ao contrário do homem ou mulher real - ela não tem direito ao não-ser e é ela própria a razão de ser da responsabilidade de homens e mulheres pelo o que há de vir (JONAS, 2006, p.94).

palavra dever. Kant distinguiu os I. Em hipotéticos e categóricos. (...) 0 I. Categórico ordena uma ação que é boa em si mesma, por si mesma objetivamente necessária, sendo portanto um princípio apoditicamente prático. (...) Os I. categóricos são os da moralidade. 
Maria da Glória F. P. D. Garcia (2007, p.79) esclarece que sob este aspecto a ética de Jonas afasta-se do modelo tradicional de direitos e deveres ligados pelo mecanismo da reciprocidade:

É a ameaça à "idéia" de Homem e não a ameaça aos homens em concreto do futuro, aos homens das gerações futuras, que impõe o nascimento de um dever novo, uma nova obrigação na responsabilidade, que abre espaço para um novo paradigma ético. Ao contrário da ética tradicional, construída na base de direitos e obrigações, e, logo, numa responsabilidade fundada na reciprocidade - a minha obrigação é a imagem de um direito de outrem -, à nova ética de que Hans Jonas fala, fundada numa responsabilidade voltada para o futuro, falta reciprocidade.

De fato, ao explicar sua teoria, o filósofo dela afasta os conceitos jurídicos de responsabilidade civil, administrativa e penal, e afirma que temos o dever zelar pela existência de futuros sujeitos de direitos - ainda que não tenhamos direitos recíprocos - com fundamento na responsabilidade pela Humanidade sob ameaça pelo excesso de poder humano gerado pelo desenvolvimento do conhecimento (JONAS, 2006, p.93 e p.165-166).

Ora, reconhecendo que Jonas demanda também a ação coletiva até uma dimensão "quase cósmica", é cabível afirmar, como o fez a jurista lusitana, que além de uma certa carga utópica, a ética de Hans Jonas é "eminentemente política, uma ética que, de um lado, demanda uma cidadania informada e ciente das consequências da sua ação e irreversibilidade, de outro demanda uma cidadania à escala global, mundial" (2007, p.8182).

\section{A ética nas políticas públicas}

Se Hans Jonas não se preocupa os com aspectos jurídicos da responsabilidade para com a Humanidade, se o seu princípio responsabilidade caracteriza-se pela voluntariedade e se a ação coletiva global pode ser considerada algo utópica, é razoável se indagar como o tema eleito se relaciona com a disciplina de políticas públicas, em especial, com a lei da PNRS.

Filosoficamente, ele próprio responde: "Se a esfera do produzir invadiu o espaço do agir essencial, então a moralidade deve invadir a esfera do produzir, da qual ela se mantinha afastada anteriormente, e deve fazê-lo na forma de política pública" (JONAS, 2006, p.44). 
Juridicamente, a professora Cristiane Derani responde lecionando que a imposição de uma política pública corresponde em última análise à substituição de uma ética por outra em construção, cujos valores encontram-se insculpidos no texto da Constituição:

\begin{abstract}
A política é assim construída, assim, no ambiente estatal, na medida em que ele seja efetivamente o tomador de decisões. Sua criação se dá a partir do reconhecimento de uma situação concreta, visando à concreção futura de valores não existentes. A finalidade é o norte pelo qual deve se guiar a política. Ele representa um valor, que estará invariavelmente inscrito no texto constitucional, representando o fundamento último da atuação ética do Estado e da sociedade. A ação impositiva e coordenada para o alcance destes fins ocorre para preencher um ambiente em que tais valores não são buscados naturalmente. Afinal, a atividade de imposição de um conjunto de ações para o alcance de determinados valores só existe porque há necessidade de rejeição e afastamento de uma ética existente e a construção de uma outra ética pautada no valor buscado.(DERANI, 2006, p.134).
\end{abstract}

Neste sentido, a Constituição Federal - CF é clara ao garantir a todos das gerações presentes e futuras 0 direito ao meio ambiente ecologicamente equilibrado e concomitantemente - clara ao exigir o dever de sua preservação e defesa tanto pelo Poder Público, como pela coletividade (art.225, caput), a fim de garantir o desenvolvimento nacional (art.3ㅇ, II) pautado pela defesa do consumidor (art.170, V) e do meio ambiente (art.170, VI).

Além disto, assim como o filósofo busca na perpetuação da Humanidade o fundamento para a responsabilidade da geração atual, a CF determina o dever de preservação e defesa do meio ambiente ao Poder Público e aos indivíduos das gerações presentes para que as gerações futuras possam existir com dignidade (art.1으, III, CF). E cabe crer ainda que dignidade da pessoa humana não corresponda apenas ao acesso a recursos naturais para a sobrevivência, mas sim toda a gama de direitos fundamentais albergados no corpo da CF, cuja concretização depende da perpetuação do que Hans Jonas denomina Humanidade.

Deste modo, o constituinte abraçou os valores éticos da proteção ambiental caros à coletividade que representava e, ao incorporá-los ao texto da Carta realizou a transformação da Política em Direito, fazendo nascer potencialmente a pretensão jurídica, a qual pode tomar a forma de ação judicial, inclusive, para a exigência da elaboração e implementação de políticas públicas (BARROSO, s/d). 
Assim, a lei da PNRS representa um primeiro passo em direção à concretização dos valores constitucionais de tutela ambiental por ela incorporados de forma expressa, tais como prevenção e precaução (art.6ำ I), desenvolvimento sustentável (art.6ํ, IV), princípio da ecoeficiência (art.6ำ V) e o direito da sociedade à informação (art.6ํ, X). Resta aos cidadãos aguardar, acompanhar e exigir resultados.

\section{Conclusões}

A lei da PNRS sinaliza que os ditames da ética tradicional não mais satisfazem à solução dos problemas da nova modernidade - tais como, a geração de resíduos além da capacidade de ciclagem natural, a contaminação do solo e da água por lixões, o aquecimento global pela combustão e o desperdício de recursos - e que estes estão sendo substituídos por uma nova forma de conduta, cujos valores últimos já se encontram no texto constitucional.

Ao estender o direito ao meio ambiente ecologicamente equilibrado às gerações futuras, a CF e a PNRS aproximam-se da ética de futuro de Hans Jonas, a qual pauta-se pela necessidade de proteção da idéia abstrata de Humanidade desligada do conceito tradicional de reciprocidade entre direitos e deveres.

O autor germânico desenvolve uma teoria filosófica - por isso não se atém a aspectos jurídicos como coercibilidade e sanção - de sorte que em um primeiro momento discorre sobre a natureza facultativa da conduta ética ambiental ("freios voluntários"). Todavia, mais adiante, ao reconhecer que somente uma ação coletiva - na realidade, globalmente conjunta - talvez possa solucionar os problemas da nova modernidade, Jonas admite que esta ética deve permear as políticas públicas que eram consideradas instrumentos neutros no passado.

Entretanto, quando o Direito incorpora a Política - como o fez no caso da lei da PNRS - transformando-a em norma jurídica cogente dotada de consequências jurídicas, inclusive criminais, deve fazê-lo com técnica e clareza suficientes aos destinatários, sob pena de frustração completa dos objetivos últimos insculpidos na CF. 
Previamente à definição de punição - seja civil, administrativa ou penal do consumidor - é preciso que seja disponibilizada a infra-estrutura necessária para a sua participação consciente no processo de descarte adequado, de reutilização e de reciclagem de resíduos.

Em outras palavras, há necessidade do preenchimento de dois pré-requisitos: um relacionado à infra-estrutura tecnológica e logística e outro relativo à conscientização do consumidor. 0 primeiro parece ter sido encaminhado pela própria lei da PNRS por meio da determinação de elaboração de planos de resíduos sólidos específicos para as esferas nacional, estadual e municipal; e o segundo deve ser direcionado por meio da lei da Política Nacional da Educação Ambiental instituída há 12 anos.

Instituída, todavia não plenamente implementada. Como dito, a instituição de uma política pública por lei representa o importante momento de seu nascimento jurídico, todavia o passo mais expressivo para a sociedade sem dúvida é a transposição para o mundo concreto, de modo que o direito de todos ao meio ambiente ecologicamente equilibrado tutelado pela PNRS depende da efetiva conscientização da relevância do papel ambiental de cada um em um contexto coletivo, independentemente de sanções, orientado pela Política Nacional da Educação Ambiental.

\section{Referências}

ABBAGNANO, Nicola. Dicionário de Filosofia. Tradução da 1a edição Alfredo Bosi. Revisão da tradução e tradução de novos textos Ivone Castilho Benedetti. São Paulo: Editora M artins Fontes, 2007.

BARROSO, Luis Roberto. Judicialiação, ativismo judicial e legitimidade democrática. Disponível em:

বhttp://www.oab.org.br/editora/revista/users/ revista/1235066670174218190.pdf >. Acesso em: 15.05.2011

BUCCl, Maria Paula Dallari. Políticas Públicas - Reflexões sobre o Conceito Jurídico. São Paulo: Editora Saraiva, 2006, p.1-49.

DERANI, Cristiane. Políticas Públicas - Reflexões sobre o Conceito Jurídico. São Paulo: Editora Saraiva, 2006, p. 131-142.

GARCIA, Maria da Graça F. P. D. 0 lugar do direito na protecção do ambiente. Coimbra: Almedina, 2007, p. 71-141. 
GERAQUE, Eduardo. Produção de lixo por morador cresce $9 \%$ no Estado de SP. Folha de São Paulo, São Paulo, 26.4.2011. Disponível em:

বhttp:// www1.folha.uol.com.br/cotidiano/907246-producao-de-lixo-por-morador-cresce-9no-estado-de-sp.shtml Acesso em 27.4.2011>

INSTITUTO BRASILEIRO DE GEOGRAFIA E ESTATÍSTICA - IBGE. Disponível em: বhttp://www.ibge.gov.br>Acesso em: 27.4.2011.

KLEIN, Naomi. M arcado mundo novo In: Sem Logo: a tirania das marcas em um planeta vendido. 4a ed. São Paulo: Record, 2004, p. 27 a 50.

LIPOVETSKY, Gilles. A felicidade paradoxal: ensaio sobre a sociedade do hiperconsumo. Trad. M aria Lucia M achado. São Paulo: Companhia das Letras, 2007, p. 11 a 97.

M CCRACKEN, Grant. Cultura e Consumo. Rio de Janeiro: Mauad, 2003.

PEREZ, M arcos Augusto. Políticas Públicas - Reflexões sobre o Conceito Jurídico. São Paulo: Editora Saraiva, 2006, p.163-176.

SODRÉ, Marcelo Gomes. Formação do Sistema Nacional de Defesa do Consumidor. São Paulo: Editora Revista dos Tribunais, 2007.

VIALLI, Andrea. Brasil aumenta em 6,8\% geração do lixo, mas coleta seletiva cresce só $1,6 \%$. 0 Estado de São Paulo, São Paulo, 26.4.2011. Disponível em:

〈http:// www.estadao.com.brestadaodehoje/20110426/not_imp710666,0.php >. Acesso em 27.4.2011.

Artigo recebido em:

25 de maio de 2011

Artigo aprovado em:

17 de agosto de 2011 